\title{
Video-assisted neck surgery (VANS) technique in Graves' disease
}

\author{
Yasser M Hamza,a MD; PhD; FRCS; Waleed AH Abul-Waja,a MD; PhD; \\ Rafik Khalil, a MD; Kazuo Shimizu,b MD
}

a) Department of Surgery, University of Alexandria, Egypt.

b) Department of Surgery, Nippon Medical School, Japan.

Co"espondence:e-mail: hamzay3@hotmail.com

\begin{abstract}
Background: The introduction of Video assisted neck surgery (VANS) technique for treatment of thyroid diseases was established by K.Shimizu in 1998. Since that time, the indications of this procedure are expanding as regarding the size of the thyroid tumors and the type of thyroid pathology.

Results: Twelve patients with small diffuse primary thyrotoxicosis underwent video-assisted thyroidectomy. The estimated thyroid weight of the study patients ranged from 18.2 to 57 with a mean of 32.5 grams. Three ofthefirst seven patients had recurrent hyperthyroidism. This was due to poor visualization and subsequently inadequate excision of the thyroid lobe away from the camera. A modification was made thereafter that corrected this defect.

Conclusion: Video-assisted near total thyroidectomy for Graves' disease is considered to be safe, effective. It gives excellent cosmetic results.
\end{abstract}

\section{Introduction:}

The introduction of video assisted neck surgery (VANS) technique for treatment of thyroid diseases was established by Shimizu in 1998.1 VANS was first used to excise discrete thyroid nodules. ISince that time, the indications of this procedure are expanding as regarding the size of the goiter amenable for resection as well as the underlying thyroid pathology.24 Compared to the total endoscopic approach using C02 insuffiation, the videoassisted approach without $\mathrm{C} 02$ insufflation has been reported more often. 5

Indications for endoscopic thyroidectomy in various studies include solitary, benign thyroid nodules, follicular and oxyphilic cell tumors and papillary micro carcinomas.6-8

The aim of most studies apart from being cosmetically superior has been to be minimally invasive offering all associated advantages such as minimal post-operative pain, rapid recovery, and low analgesic requirement.9,10

Interms of invasiveness none of the distant sites of access prove to be truly minimally invasive as the extent of dissection is much more compared to a focused, direct approach. Their popularity has however persisted and increased for the sake of cosmesis.

VANS would be very suitable for Grave's disease which usually affects young females and is typically associated with small sized goiter.6 Concerns have, however, been raised regarding the feasibility of the technique in view of the high vascularity of the gland and its efficacy in controlling the hyperthyroidism.

Aim of the study:

The aim of the study is the assessment of the feasibility, safety and efficiency ofVANS in the treatment of Grave's disease of thyroid gland.

Patients and methods:

Study design: This is a prospective nonrandomized clinical trial with informed written consent signed by all patients.

Study population: The study included 12 patients with Grave's disease presenting to the Department of Surgery II, Nippon Medical School, Tokyo, Japan and to the Head \& Neck 
\& Endocrine Surgical Unit, Department of General Surgery, Alexandria Main University Hospital, Egypt. The patients were selected following the following inclusion criteria:

- Thyroid lobes with maximum diameter of 55 $\mathrm{mm}$.

-No history of neck surgery or neck irradiation. - Absence of thyroiditis.

All patients underwent complete medical history and clinical examination.

Investigation included hematological analysis, thyroid hormone assay, ultrasound of the neck and laryngoscopy. Detailed operative data, postoperative course and complications were collected. Cosmetic result and patient satisfaction were recorded.

Statistical analysis:

All data were analyzed by using the Statistical Package for the Social Sciences Version 13 software (SPSS Inc, Chicago, IL). Quantitative values are expressed as means \pm standard deviation (SD).

Results:

All patients were females. Age ranged between 20 and 42 years with a mean of 28.1 years. None of the studied patients suffered from associated medical conditions.

Patients had video assisted thyroidectomy using the infraclavicular approach and gasless skin lifting technique. I Seven patients had subtotal thyroidectomy and five had near total thyroidectomy.

There was high incidence of recurrence among the first seven cases $(317,42.9 \%)$, due to poor visualization and subsequently inadequate excision of the thyroid lobe away from the camera. A modification was made thereafter which corrected this defect: The camera was moved to a second port on the other side while excising the corresponding lobe. No patient developed recurrent hyperthyroidism after introduction of this modification to the technique.

Table(1) summarizes the data of the study patients. The average estimated weight of the thyroid was 32.5 grams. The average amount removed by VANS was 30.4 grams. The average estimated weight left was 2 grams. Operative time ranged from 43 to 196 minutes with a mean of $67 \pm 34.32$

There was no permanent nerve injury in the study group. Three patients suffered from transient vocal cord paralysis. No patient suffered from hypocalcemia postoperatively.

Table (1): The operative data of the 12 patients.

\begin{tabular}{|c|c|c|c|c|}
\hline Case no. & Age & g resected & gremaining & Postop h \\
\hline 1 & 42 & 13.7 & 4.5 & eu \\
\hline 2 & 23 & 41.1 & 2 & eu \\
\hline 3 & 28 & 12.8 & 2 & eu \\
\hline 4 & 20 & 51.1 & 3 & hyper \\
\hline 5 & 23 & 23.8 & 2 & hyper \\
\hline 6 & 34 & 33.4 & 2.5 & eu \\
\hline 7 & 31 & 37.6 & 2.3 & hyper \\
\hline 8 & 28 & 17.7 & 1.5 & hypo \\
\hline 9 & 34 & 25.1 & 1 & hypo \\
\hline 10 & 29 & 19.8 & 1.5 & eu \\
\hline 11 & 31 & 33.1 & 1.5 & eu \\
\hline 12 & 24 & 56 & 1 & hypo \\
\hline
\end{tabular}




\section{Discussion:}

Thyroidectomy for Grave's disease is commonly carried out for young females for whom the cosmetic appearance, in a visible region as the neck, would be of great importance.11

Video-assisted thyroidectomy has been characterized by the considerable number of accesses described (neck, axilla, breast, chest). No approach has proven superiority over the others. 12 The selection of the approach would therefore depend on the way patients of a given population customarily dress.

In spite of the well-known difficulties encountered when operating on thyroid with Grave's disease, the infraclavicular approach was found to be safe and efficient in dealing with such disease. The ability to use traditional surgical instruments and to introduce the surgeon's finger to the operative field helps in orientation and hemostasis. This also allows for shorter operative time and virtually eliminates the need for conversion.

Futhermore, the generosity of the infraclavicular incision allows for operating on relatively larger goiters thus expanding the indications for this operation.13,14

Studies have already demonstrated that this approach is advantagious not only in terms of cosmetic result, but also in analgesic requirements and post-operative recovery, with a similar complication rate_11,14

\section{References:}

1- Shimizu K, Akira S, Tanaka S: Videoassisted neck surgery: Endoscopic resection ofbenign thyroid tumor aiming at scarless surgery on the neck. Journal of Surgical Oncology 1998; 69: 178-180.

2- Muenscher A, Dalchow C, Kutta H, Knecht R: The endoscopic approach to the Neck: A review of the literature, and overview of the various techniques. Surg Endosc 20I0; Dec 7 [PMID: 21136119].

3- Byrd JK, Nguyen SA, Ketcham A, Hornig J, Gillespie MB, Lentsch E: Minimally invasive video-assisted thyroidectomy versus conventional thyroidectomy: A costeffective analysis. Otolaryngol Head Neck Surg 2010; 143(6): 789-794.
4- Lombardi CP, Raffaelli M, De Crea C, D'Amore A, Bellantone R: Video-assisted thyroidectomy: Lessons learned after more than one decade. Acta Otorhinolaryngol Ita/2009; 29(6): 317-320.

5- Chowbey PK, Soni V, Khullar R, Sharma A, Baijal M: Endoscopic neck surgery. $J$ Minim Access Surg 2007; 3(1): 3-7.

6- Moural M, Pugin F, Elias B, Malaise J, Coche E, Jamar F, et al: Contribution of the video assisted approach to thyroid and parathyroid surgery. Acta Chir Belg 2002; 102: 323-328.

7- Miccoli P, Berti P, Raffaelli M, Materazzi G, Baldacci S, Rossi G: Comparison between minimally invasive video assisted thyroidectomy and conventional thyroidectomy: A prospective randomized study. Surgery 2000; 130: 1039-1043.

8- Takami H, Ikeda Y: Total endoscopic thyroidectomy. Asia JSurg 2003; 26: 8285.

9- Mourad M, Pugin F, Elias B, Malaise J, Coche E, et al: Contributions of the video assisted approach to thyroid and parathyroid surgery. Acta Chir Belg 2002; 102: 323327.

10-Bellantone R, Lombardi CP, Bossola M, Boscherim M, De Crea C, Alesina PF, et al: Video assisted vs conventional thyroid lobectomy: A randomized trial. Arch Surg 2002; 137:301-305.

11-Duh QY: Presidential address: Minimally invasive endocrine surgery - standard of treatment or hype? Surgery 2003; 134: 849857.

12-Slotema ET, Sebag F, Henry JF: What is the evidence for endoscopic thyroidectomy in the management of benign thyroid disease? World J Surg 2008; 32: 13251332.

13-Lombardi CP, Raffaelli M, Princi P, Lulli P, Rossi ED, Fadda G, et al: Safety of video-assisted thyroidectomy versus conventional surgery. Head Neck 2005; 27: 58-64.

14-Lombardi CP, Raffaelli M, De Crea C, D'Amore A, Bellantone R: Video-assisted thyroidectomy: Lessons learned after more than one decade. Acta Otorhinolaryngologica ltalica 2009; 29: 317-320. 